\section{MODERN METHODS OF TREATING INFECTIVE CONDITIONS OF THE THROAT.}

BY MEREDITH YOUNG, M.D., C.M. EdIN., D.P.H., D.S.Sc., \&C.,

BARRISTER-AT-IAW ; LATE MEDICAL SUPERINTENDENT, STOCKPORT CORPORATION HOSPITALS.

As late medical superintendent of an infectious diseases hospital in which throat conditions of an infective or at least a bacterial character were of everyday occurrence I have for many years been exercised as to the best methods of combating such conditions, both from the curative and preventive points of view. Practice in this matter may be said to consist chiefly in the application of antiseptics by means of gargle, swab, spray, or douche, and practice varies in intensity from the squeamish use of a very mild gargle to the intrepid employment of a strong germicide under an an sesthetic. From both the preventive and curative points of view the annibilation, or at least the inhibition of growth, of the causal organism or organisms in such conditions is obviously the first thing at which to aim.

It is well known that what occurs in the case of true diphtheria bacilli during their growth on the fauces and throat-the formation, absorption, and circulation of toxic products-can also occur in the case of various staphylococci, streptococci, pneumococci, yeasts, and the like. We have not as yet for the latter conditions a mode of attack from within such as we have in the use of diphtheria antitoxin, except the use of antistreptococcic serum which I am of opinion is of decided value in many infective throat diseases. We are therefore compelled to rely upon methods which destroy the local toxin-factory or weaken its operatives so that their output is lessened. This is of especial importance in scarlet fever-a disease which $I$ have long held to be strictly analogous to diphtheria in its pathology, there being a local bacterial factory in the throat from which toxin is distributed throughout the system to produce the secondary manifestations of the disease-lymphadenitis, nephritis, otitis, rheumatism, $\& 3$. It appeared to me, therefore, that as complete a test as possible, primarily bacteriological, of the value of the various antiseptics commonly used for the "disinfection" of the throat and of the various methods of applying these antiseptics would be of considerable interest. My first idea for the bacteriological test was to plant artificially some easily recognisable bacillus like the bacillus prodigiosus on the fauces and then to treat it with various solutions and note its diminution or disappearance. But on consulting Professor S. Delépine of the Pablic Health Laboratory, Manchester, whose kindness to anyone venturing on original investigation is notorious, I found that this had been tried with unsatisfactory results and that not the least objection to it was that it had at times resulted in unpleasant consequences to the subject. Obviously, as was pointed out to me, much more valuable results could be obtained by the observation of the behaviour of some bacterium actually growing on the throat than of some extraneous organism which might find the throat per $s e$ an undesirable residence. It was accordingly decided that I should endeavour first to find a throat which possessed fairly uniform bacterial contents and for this purpose I took swabs of a few throats for examination by Profiessor Delépine. The swab, which was of the kind ordinarily used in the diphtheria outfit at the health office, was rubbed gently first over one anterior pillar of the fauces and then over the other; it was then immediately labelled and sent off for examination, care being taken to send none at week-ends or during holidays when the delay would cause multiplication of organisms.

The method adopted by Professor Delépine for the examination of these swabs was to make an emulsion from each one in 5 cubic centimetres of sterile water, and from this to make a further dilution enabling agar plate cultures at $37^{\circ} \mathrm{C}$. to be made containing $\frac{1}{5} \mathrm{th}, \frac{7}{5} \overline{0} \mathrm{th}, \frac{1}{5} \mathrm{~J}_{\mathrm{j}} \mathrm{th}$, and $\frac{1}{5} \overline{5} \overline{0}$ th of the whole. The swabs were obtained under as nearly as possible similar conditions. They were not packed in ice to prevent or to lessen multiplication in transitu, but as all were sent in precisely the same manner the variations obtained are, I think, fairly attributable to the causes assigned. Care was taken to use the same amount of pressure on the mucosa when using the swabs, for any variation would naturally

result in the swab picking up more or fewer bacteria in its journey. Some part of the variation in the results obtained is undoubtedly due to a difference in the amount of pressure employed, a matter naturally most difficult to control. Quantitative bacteriological work is at best an uncertain thing but the results obtained indicate that in these experiments the care taken in collection and examination has not been thrown away. Most of the colonies obtained were those of streptococci and not staphylococcias had been anticipated. The first throats examined were those of three hospital nurses, in the first of which (Nurse G) I had a month previously excised a portion of one tonsil. All presented apparently normal fauces and the divergent results obtained are probably the consequence of the atmosphere to which they were exposed-that of a scarlet fever ward containing occasionally diphtheria, rhinorrbœa, otorrbœu, cervical abscesses, \&c.- the usual accompaniments of scarlet fever.

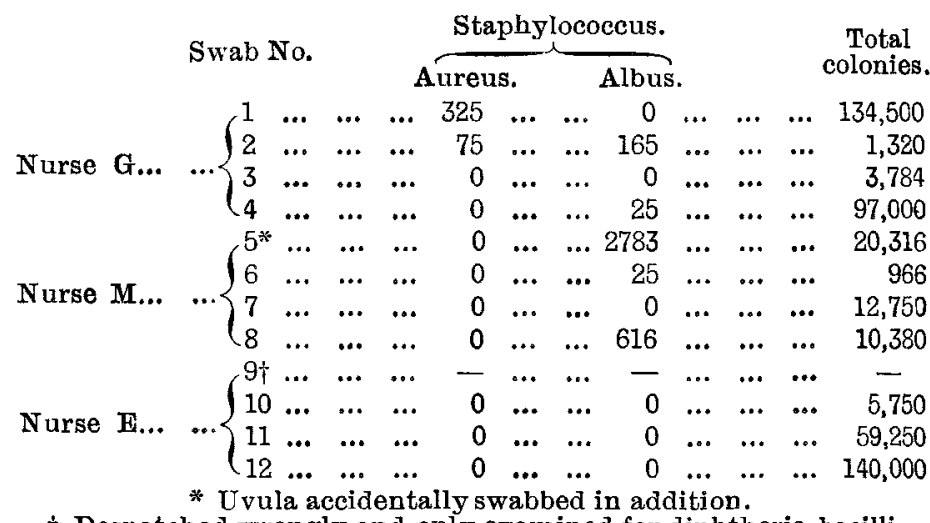

$\uparrow$ Despatched wrongly and only examined for diphtheria bacilli.

These throats had to be abandoned for experimental purposes but the results are nevertheless interesting, if for nothing else at least for showing what a happy huntingground for microbic life the fauces are. It was accordingly decided to select a throat not so liable to accidental contamination. Swabs Nos. 13 to 17 were taken from the throat of an office clerk, aged 22 years, in good health and a nonsmoker. The first three and the last were taken at 11 o'clock in the morning and No. 16 at 4 in the afternoon. In the case of the last named the tongue was very slightly touched with the swab, which probably accounts for the increased number of organisms present. Swab No. 17 was from one side of the fauces only. The results obtained were as follows :-

Swab No.

$$
\begin{aligned}
& \text { Staphylococcus } \\
& \text { aureus. } \\
& \ldots \quad \ldots \quad 0
\end{aligned}
$$

$\begin{array}{lllll}13 & \ldots & \ldots & \ldots & 0 \\ 14 & \ldots & \ldots & \ldots & 0\end{array}$

$\begin{array}{lllll}15 & \ldots & \ldots & \ldots & 0 \\ & \ldots & 0 & 0\end{array}$

$16^{*} \quad \ldots \ldots c c c c$

$17 \dagger$

* Tongue accidentally touched.

Thus all the swabs contained a large number of organisms, and though there was considerable variation between them this was not so great as in the previous cases. Fxcluding Nos. 16 and 17 the average bacterial content of the swab was about 300,000 . There was thus plenty of room for full appreciation of the diminution which it was anticipated would follow the application of antiseptics.

The organisms classed as "others" were streptococci which in the untreated throat were found along with the micrococcus tetragenus. After treatment the micrococcus tetragenus greatly predominated, showing that the streptococci were more easily eliminated by the reagents employed. It was accordingly decided to use this as the testthroat.

Gargling was the first method adopted and it may be remarked that the subject was an adept at this. After the use of the antiseptic the throat was invariably gargled once thoroughly with sterilised. water, on Professor Delépine's advice, in order to prevent any of the antiseptic adhering to the swab and thus interfering with growth of the microorganisms. A curious result was at once noted-namely, that after the use of the gargles staphylococcus albus frequently appeared and rarely staphylococcus aureus, although both of these had been absent prior to gargling. The only theory one could form to account for this was that the gargling process had forced the tissues and the bacteria attached to them out of their normal situation 
and the swab had picked the latter up in its journey round the anterior pillars. Swabs Nos. 18 to 20 show this markedly.

\begin{tabular}{|c|c|c|c|c|c|c|c|c|c|c|c|c|}
\hline \multirow{2}{*}{\multicolumn{2}{|c|}{ Swab No. }} & \multirow{2}{*}{\multicolumn{3}{|c|}{ Antiseptic used. }} & \multicolumn{6}{|c|}{ Staphylococcus. } & \multirow{2}{*}{\multicolumn{2}{|c|}{ Others }} \\
\hline & & & & & \multicolumn{3}{|c|}{ Aureus. } & \multicolumn{3}{|c|}{ Albus. } & & \\
\hline & ... & .. & $\mathrm{HgCl}_{2} 1$ in 2000 & ... & ... & 0 & ... & ... & 125 & $\cdots$ & $\ldots$ & 675 \\
\hline & ... & $\ldots$ & $\mathrm{HgI}_{2} \mathrm{I}$ in 2000 & $\ldots$ & $\ldots$ & 0 & $\ldots$ & $\ldots$ & 50 & $\ldots$ & ... & 75 \\
\hline & ... & ... & Cyllin 1 in 1000 & $\ldots$ & $\ldots$ & 0 & ... & $\ldots$ & 90 & $\ldots$ & ... & 102 \\
\hline & ... & ... & ... Izal 1 in 800 & $\ldots$ & $\ldots$ & 0 & $\ldots$ & $\ldots$ & 15 & ... & $\ldots$ & 45 \\
\hline
\end{tabular}

These results were undoubtedly excellent as compared with those obtained from the normal throat and show the probable value of these now well-proved antiseptics ; izal stands well out as a germicide but the subject complained of the pain caused by it. Amongst other antiseptics examined by the gargling process were the following :-

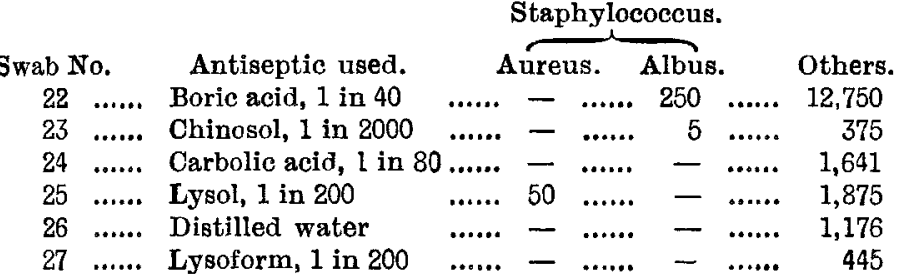

There are no exceptional results here therefore except in the case of boric acid which certainly ought to stand con. demned for this purpose. Lysoform and chinosol appear to be the best, but the former proved irritating ; distilled water was found equal to most of the commonly adrocated anti septics. One is inclined to the conclusion that the action of a gargle is merely that of a mechanical flushing of the parts and with the exception of a few very strong germicides (Nos. 18 to 21) it appears not to be of much consequence what is used for the purpose.

Douching.-It is a curious thing that so few nurses know how to douche a throat properly. I always use now a wheeling table with two glass shelves and with an iron standard ranning up from one corner to support a syphon douche can containing the lotion to be used. A long rubber tabe come from this and is fitted with a pinch-cock; glass end-pieces are attached to the rubber tube and there are sufficient of these in a lotion bowl on one of the shelves to allow of thorough disinfection and cleansing. The child is wrapped firmly in a sheet, his arms being confined ; the nurse sits the child up in bed and places her left arm round his neck so as to fix his head which is pressed against her left side. The head of the child is then bent forward over the receiving bowl. The nurse takes the tube with the pinch-cock in her right hand and passes the end-piece into the child's mouth betneen his back teeth (thus avoiding any interference by the tongue). The wrapping up of the child is a most essential part of the procedure, for it prevents struggling and thus prevents exhaustion, sometimes a vital consideration.

The only two substances tried were hydrargyri perchloridum 1 in 1500 (made up with a little glycerine and tinctura lavandulæ composita) and liquor calcis chlorinatæ 1 in 200 , followed in each case by sterilised distilled water. The results are good as shown in this statement :-

\begin{tabular}{|c|c|c|c|c|}
\hline & \multicolumn{2}{|c|}{ Staphylococcus. } & \multirow{2}{*}{\multicolumn{2}{|c|}{$\begin{array}{c}\text { Total } \\
\text { colonies. }\end{array}$}} \\
\hline & Aureus. & Albus. & & \\
\hline & $\ldots \quad 25$ & ..... - & ...... & 60 \\
\hline iquor calcis chlorinatæ ... & $\ldots \quad-$ & ...... & $\ldots \ldots$ & 98 \\
\hline
\end{tabular}

This method must therefore stand as one to be recommended for bacteriological cleansing of the fauces, but is hardly adapted for anything except hospital use on account of the difficulty of the operation and the dangers of it when improperly done.

Srvabbing._- Prima facie this would appear the most thorough way of bacteriologically cleansing the fauces as well as of insuring that remedial agents were closely applied. In practice I have found it of greater value than any other method. In order to obtain the best results the patient should be placed with the head well back over a pillow in pretty much the same position as for removal of adenoids so as to prevent any liquid expressed from the swab passing into the larynx. The swabs used should be nearly as large as a walnut and can conveniently be made of absorbent wool carefully fastened into an ordinary sponge-holder, or tightly twisted over a wooden holder with a roughened end and should be firmly and rapidly passed with a rotary motion not only over the fauces but if possible into the naso-pharynx, at least three or four swabs being used. Some nurses manage exceedingly well with a little lint wrapped over the forefinger, but this may result in a "poisoned wound " unless the nurse is extremely careful. The results obtained bacteriologically emphasise the value of this mode of treatment. Swab C3, taken after gentle swabbing with liquor calcis chlorinatæ 1 in 200, showed the following:-Staphylococcus aureus, none staphylococcus albus, 10 ; total colonies, 75. The other organisms were the tetracoccus as before and some streptococci, yeasts, and sarcinæ, probably expressed from hiding places. After swabbing with 0.5 per cent. formalin there were only 30 colonies, all of the staphylococcus pyogenes albus, found capable of growth, an excellent result; the subject, however, did not care for the treatment, which he said was most irritating to the throat, nose, and eyes.

A very useful lotion in practice, inexpensive and unirritating, was one I had seen advocated for use for another purpose-namely, persistent otorrhœa-by a recent writer in one of the leading medical weeklies. Its composition is as follows : Acidum boricum, 1 ounce; spiritus vini rectificatus, $2 \frac{1}{2}$ ounces; glycerinum purum to 8 ounces. After swabbing the fauces once with this and then with sterilised water the bacterial flora of the anterior pillars were reduced to 25 total colonies and there was an entire absence of staphylococci and streptococci. I can therefore recommend this as a swabbing agent of very considerable value.

Antiseptic lozenges.-Pharmacy has certainly not developed this form of medicament to any degree of elegancy. The B.P. lozenges of the antiseptic variety-e.g., trochisci acidi carbolici and trochisci eucalypti gummi-may be tolerated by adults but children have to be literally forced to take them and adopt all kinds of tricks to get rid of them. Many adults are children in this respect. My own experience of them is that the children are to be commended rather than blamed for their discrimination. Trochisci potassii chloratis are slightly more palatable and tolerable but I have never experienced any good results with them. On one occasion when a patient used them very freely poisoning resulted. At one time I tried making lozenges of my own after the style of what I believe are termed "fondants," introducing a small percentage of antiseptic. For those who have sufficient time to devote to this form of pharmacy I submit the following recipe. Take one pound of icing sugar and the white of one egg ; beat the egg till it is liquid; work the sugar into it ; add the antiseptic ; $\mathrm{mix}$ thoroughly and knead with the hand like dough; roll ont into thin cylindrical masses; cut up into the requisite number of fondants, place on a plate, and allow to dry in the air. They do not keep well but have a tendency to go hard and lose efficiency in the case of volatile antiseptics.

The sole object of a medicinal lozenge is to keep the part of the mouth or throat one desires to treat bathed for a time in the drug dissolved in the saliva. The main point, therefore, to receive attention in the making of a medicinal lozenge is that it should be so temptingly constructed that children in particular will take pleasure in its consumption and therefore keep it in the mouth for a long time. I know of only one medicated lozenge-formamint tablets-which meets this requirement. My hospital children are not told they are to be given lozenges but that if they are good they shall have some "toffies"-a little dodge which works extremely well in practice. When they are subsequently given these formamint tablets they take them greedily and not infrequently actually cry for them. The only times at which any trouble at all has been experienced in their administration have been when there was acute tonsillitis or angina, and here of course the swallowing of anything at all is a painful process. Even in such cases, however, perseverance usually results in the taking of a few and then the painfulness disappears fairly rapidly and they are well taken. The introduction of a powerful and acrid drog like formic aldehyde into a palatable lozenge is certainly a pharmaceutical triumph. These tablets are stated to be a chemical combination of formic aldehyde with lactose in the proportion of 001 gramme of formaldehyde in 1 gramme of the total combination; citric acid and probably some flavouring agents are added. They evolve, so it is stated, nascent formic aldebyde in the mouth, and now and then one gets a slight burning sensation and the peculiar taste of this substance, though this is usually only noticeable with the first one taken. They produce a pleasing flow of saliva and the formaldehyde dissolved in this is carried by the process of sucking and swallowing to the various crypts and recesses of the mouth and throat. The amount of formaldehyde in 
each tablet is small and, in my opinion, the manufacturers have been well advised in proceeding on these lines. The pharmacist who crowds a large amount of antiseptic into one lozenge will not find his preparation appreciated, even if it be tolerated. Surely it is an easy matter to distribute the same amount in two or three lozenges and instruct the patient to take them more frequently.

The fact that the mouth, fauces, and pharynx are well supplied with muscles is frequently lost to sight, as is also the fact that certain very complicated movements are involved in the act of deglutition. A brief résumé of the processes of mastication and deglutition may not therefore be out of place here. Prior to actual swallowing-i.e., whilst the morsel is anterior to the isthmus of the fauces-it is turned over and over by the muscles of the lips, tongue, and cheeks, and is bandied about from one part to another of the oral cavity. The front of the tongue is then pressed against the back of the upper incisors, the back portion of the tongue is heaved up with a wave-like motion, and the now moistened bolus is carried, as it were, on the crest of the wave, through the isthmus of the fauces, the pillars of which first open apart to allow of its passage and then contract so as to partition off the buccal from the pharyngeal cavity. At the moment of "heaving" of the tongue certain other complicated actions take place by means of which the pharyngeal is shut off from the laryngeal channel. The constrictors of the pharynx immediately grasp the food morsel, the velum palati is elevated, and the orifices of the Eustachian tubes, which are probably closed during the resting or inactive condition of the pharynx, are now opened. The act of deglutition is finally completed by the passage of the morsel into the cesophagus and the onset of peristaltic action.

This semi-dissertation on the physiology of deglutition is not without important indications for treatment of buccal, faucial, and pharyngeal conditions. When the mouth is opened for douching, swabbing, or gargling, the parts, particularly the fauces, are at once thrown into an unnatural position, and many of these bacterial hiding-places are at the same instant covered up and protected from contact with the reagent applied. Moreover, the reagent can only be in contact with the parts to which it is applied for an inconsiderable period, and probably what little good results from such unnatural methods is effected by the reagent left on the parts mingling afterwards with the saliva and being carried in the manner just described to other parts. When lozenges or soluble tablets are used the mouth, fauces, \&c., are not forced into any artificial position; the reagent dissolved in saliva and carried along by the muscular movements of deglutition flows for a considerable period over the surfaces to which it is desired to apply it; and what is of the greatest importance in diseases of these parts associated with the presence of bacteria the antiseptic is enabled by these muscular movements to follow the bacteria to their anatomical lairs.

I therefore wish to enter a strong plea for the elaboration of the lozenge treatment of mouth and throat diseases, to say nothing of other diseases where one wishes to give to a patient a drug to be taken, for example, during business hours, on journeys, \&c. The dry concentrated form of drug meets many of these requirements and has many advantages, but it has this amongst other disadvantages, that the patient gulps it down whole (particularly if it be disagreeable) and it may lie for some time adhering to the stomach or intestinal wall where, if it be at all of an irritant nature, it is bound to produce discomfort and ill-effects on the mucosa. In the form of a palatable lozenge none of these bad effects need be feared. Further than this, I am a great believer in what physiologists term the "summation of stimuli" and I cannot help the thought that heroic drugging would seldom be necessary if some such means as the one suggested were adopted for the administration of frequent small doses of medicine. However, this is rather a digression.

Knowing the powerful germicidal effects of formaldehyde and observing the excellent results recorded of it by Dr. Daus $^{1}$ in acute follicular tonsillitis, mumps, acute submaxillary gland inflammation, and even in middle-ear disease, and the very good report of Dr. Piorkowski of the Bacteriological and Physiological Institute of Berlin, I $\mathbf{d}$ termined to test these formamint tablets on the same lines as those on which gargles, sc., had been tested. I met with the most encouraging results. In a swab taken immediately after the sucking of one formamint tablet no bacteria whatever appeared, even in the dilution of one-fifth of the emulsion; in a swab taken ten minutes afterwards 35 micro-organisms grew, and in one taken 30 minutes afterwards 150 were present. There was, moreover, a total absence of staphylococci in all three swabs, the organism simulating the micrococcus tetragenus being the only one to resist the remedy and appearing in the two later swabs. This result is a little inconsistent with that obtained on swabbing with 1 in 200 formalin (vide supra) so that I repeated it in part with the following result. The patient's throat was first tested in order to get the bacterial contents of the anterior faucial pillars and the posterior pharyngeal wall. Next he was instructed to suck two formamint lozenges-one every half hour-and then to gargle with sterilised water. The fauces and pharynx were then examined and the results are shown in the following statement :-

Colonies Capable of Growth on Agar Plates at $37^{\circ} \mathrm{C}$. Total Staphylococcus Tetrads. Streptococci.
colonies. albus.

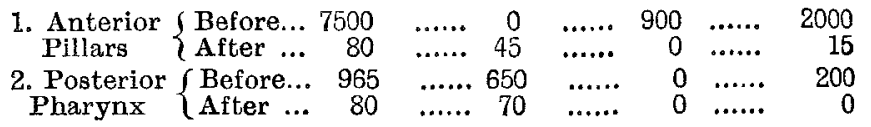

These results must be classed as distinctly excellent. I next proceeded to test two of the B.P. lozenges

Swab $C 1$ was taken precisely as the other swabs, a few minutes after the slow sucking of trochisci eucaly pti gummi, B.P., the throat being gargled immediately afterwards with sterilised water. The colonies yielded were: staphylococcus aureus, none; staphylococcus albus, none; total colonies, 6600 .

Swab C2 was taken after similar treatment with trochisci acidi carbolici B.P. and yielded : staphylococcus aureus, none; staphylococcus albus, 1500; total colonies, 41,000. The chief organism found was a tetracoccus closely resembling the micrococcus tetragenus.

The difference between these two lozenges is in my opinion due to the astringent action of the eucalyptus in closing up microscopic hiding-places for bacteria.

Clinical results. - These have been obtained chiefly in connexion with scarlet fever, diphtheria, "hospital throats," and the like. In no class of case is the hygiene of the mouth and throat of more importance than in scarlet fever. Left alone, many a case of this disease, simple at the onset, drifts into the septic variety; the organisms accompanying the specific one (whatever that may be) begin to flourish and invade accessory parts, setting up otorrhœa, rhinorrhœa, post-scarlatinal diphtheria, cervical lymphadenitis, \&c. The most important line of treatment, therefore, in scarlet fever is, in my opinion, to keep the mouth and fauces in a condition unfavourable to the growth of these organisms. In the case of fauces already septic swabbing and douching are essential to remove the mucus and exudation which are almost always present. It is useless to apply any curative until this has been done.

In the septic or anginous variety of scarlet fever the tonsils and soft palate are cedematous and covered with mucus, and the condition is usually accompanied by ichorous nasal discharge. In such cases there are generally present some ulcers difficult to localise at first and most commonly situated in the angles between the uvala and palatal arches. Treatment is most difficult in these cases on account of the pain necessarily associated with it. But my experience has been that the best method is to begin with a very thorough cleansing of the parts, wrapping the child firmly in a blanket, using a mouth.gag if necessary, and swabbing first of all with some weak antiseptic such as 1 in 1500 hydrargyri perchloridum made up with a little glycerine and tinctura lavandulæ composita, then douching with the same solution, and afterwards putting the patient on to a liberal supply of formamint tablets. If the child can be encouraged to take these it will not be necessary to repeat the forcible swabbing and douching more than a very few times, and indeed the less it is done the better, for an ulcerated part cannot be expected to heal if we use measures that are bound to remove some, or perhaps all, of the newly formed epithelium which is growing over the ulcer. The swabbing, as the bacteriological examination already quoted shows, removes most of the presumably causative bacteria, and the mild antiseptic contained in the tablets 
mentioned may be relied upon to prevent their subsequent multiplication.

Gegner ${ }^{2}$ condemned the use of formic aldehyde as a gargle because of its irritating effects on mucous membranes, a fact well known to all who have used the substance. It is a fact that the use of formic aldehyde for swabbing, douching, or spraying the fauces causes the appearance of a bright red congestion in the mucosa and frequently in sensitive patients irritation of the nose and even of the eyes, accompanied by more or less watering. But after the use of formamint tablets I have had none of these signs of irritation and only very faint reddening of the buccal and faucial mucosa.

There was a fear that the use of formic aldehyde even in the very small amount present in a lozenge, such as that named, might increase the liability to albuminuria when used in scarlet fever, but the figures show that this is not at all the case. Out of 300 cases taken over a period of about two and a half years and treated without formamint 48 cases of albuminuria (i.e., 16 per cent.) were recorded of varying duration. Of 100 cases treated with the tablets given at the average rate of about 12 per day for about a week at a time only seven cases (or less than half the above rate) are recorded. Moreover, in several instances the tablets were continued throughout the whole of an attack of albuminuria and the albumin cleared up under suitable treatment during their administration.

It appears to me highly probable too that the employment of these tablets has prevented the development of septic conditions and their consequences. The following figures certainly seem to bear out this statement:-

Cases in which Formamint was not Used.

No. of Percentage cases. occurrence.

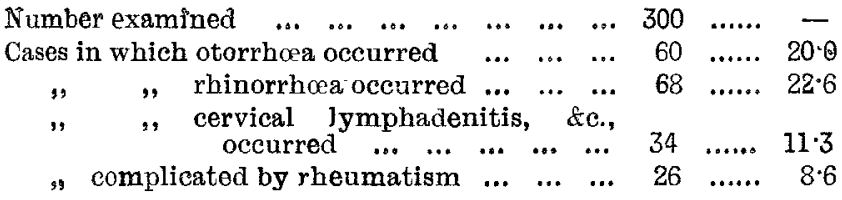

Cases in which Formamint was Used.

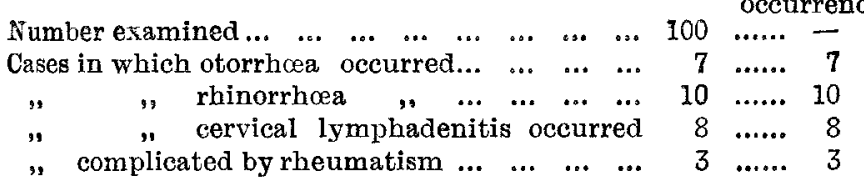

A few summarised records of cases of scarlet fever may serve to emphasise the utility of this form of medication.

CASE 1.-The patient, aged seven years, first became ill on Feb. 4th rash on Eeb. 6th; hospital Feb. 6th. Throat deeply congested lacunar exudate on tonsils and fauces. Temperature, evening, $108.6^{\circ} \mathbf{F}$. Formamint, one every hour. Feb. 7 th : Temperature, morning 100.6 morning $98^{\circ} 4^{\circ}$, evening $99^{\circ}$; throat perfectly normal. Uninterrupted recovery.

CASE 2.-The patient, aged seven years, first fell ill on Feb. 8th a rash on the 10th; hospital on the 11th. Temperature, evening, 101.80 F. Tonsils deeply congested and swollen; some doubtful pultaceous exudate left anterior fauces; thin, acrid, nasal discharge excoriating anterior nares and lips. Throat swabbed and douched with hydrarg. perchlor. 1 in 1500. Formamint one every hour. Feb. 12th: Diphtheria bacilli in nasal discharge and faucial swab. Congestion of Diphtheria bacilli in nasal discharge and faucial swab. Congestion of
tonsils, \&c., lessened. Temperature, morning $101^{\circ}$, evening $101.4^{\circ}$. tonsils, \&c., lessened. Temperature, morning 101\%, evening $101^{\circ} 4^{\circ}$. morming $99.2^{\circ}$, evening $982^{\circ}$. Congestion quite gone; some exudate morning $99.2^{\circ}$, evening $98.2^{\circ}$. Congestion quite gone; some exudate
still adhering. Formamint one every two hours. Feb. 14th : temperature, morning $99^{\circ}$, evening $98^{\circ} 2^{\circ}$; throat normal. Slight rheuperature, morning $99^{\circ}$, evening $92^{\circ}$; throat normal, Slight rheunot given in this case.)

CASE 3. - The patient, aged three years, first fell ill on August 25th ;
not given in this case.) rash on the $26 t h$; removed to hospital on the 27 th. Temperature, evening, $1022^{\circ} \mathrm{F}$. Fauces covered with wash-leathery membrane; slight nasal discharge. Antitoxin 6000 units; formamint one every
hour. August 28th: temperature, morning $100.6^{\circ}$, evening $103 \cdot 2^{\circ}$. Throut Awab negative; nasal swab contained short diphtheria bacilli. Antitoxin 6000 units; formamint as before. Fauces still coated with exudate. August 29th : temperature, morning 100.20, evening $99^{\circ} 4^{\circ}$. Fauces almost clear; nasal discharge much less. August 30th : tem perature, morning $99^{\circ} 6^{\circ}$, evening $98^{\circ}$. Fauces quite clear; nasal discharge almost imperceptible. August 31st: temperature normal. No diphtheria bacilli in three consecutive throat or nasal swabs.

CaSE 4.-The patient, aged seven years, first fell ill on July 13 th rash same day ; hospital on the $14 \mathrm{th}$. Temperature, evening, $103.4^{\circ} \mathrm{F}$. Throat deeply injected throughout, tonsils considerably swollen, no exudate. Intense pain on swallowing. Formamint one every hour ; badly taken at first, later with fair comfort; no other treatment. July 15 th : temperature, morning $102 \cdot 4^{\circ}$, evening $102 \cdot 6^{\circ}$. Throat some-
what less congested; swallowing much easier. Formamint as before. July 16th : temperature, morning $100^{\circ} 4^{\circ}$, evening $99^{\circ}$. Throat quite normal; general condition excellent.

2. Münchener Medizinische Wochenschrift, 1893, p. 599.
CASE 5.-The patient, aged six sears, first fell ill on Dec. 22nd; rash on the 23rd; hospital on the 24th. A thin, poorly nourished child. Tongue soft. flabby, and crossed with deep sulci filled up with masses and ead epithelium; buccal and labial mucosa and gums soft, spongy, ture, evening, $102.8^{\circ} \mathrm{F}$. Mouth swabbed out with glyc. boracis every toure, hours. Formamint tablets taken with difficulty ; a few only. Dec. 25th: Temperature, morning $101^{\circ} 80^{\circ}$, evening $101^{\circ} 6^{\circ}$. Mouth and tongue somerath toin sul very paintul. Mouth swabbing stopped. Formamint taken rather better, bout ten during day. Dec. 26th: Temperature, morning 101\% evening $100 \cdot 6^{\circ}$. Ulcers on buccal mucosa disappeared. Tongue still very raw and painful. Dec. 27th : Formamint one every hour. Temperature normal. Gums and buccal mucosa frm and normal in perfectly normal except for thin bluish-white lines showing where perfectly norm

In one case of syphilitic alceration of the tongue in a congenitally affected child, three years old, also suffering from scarlet fever, I had the best results from the use of formamint tablets, conpled, of course, with specific constitutional treatment. I have also had temporary benefit from their use in post-nasal follicular hypertrophy or adenoid growth; the nasal tone of voice and the mouthbreathing have both been improved for the time.

One cannot, of course, speak with certainty of the preventive properties of any drug, but a case which came under my daily observation may be cited as showing that in these formalin-containing tablets we have probably a useful prophylactic agent. A boy who had gone on a visit to a house developed pronounced mumps after being there a few days. There was no possibility of isolating him, and there were two other children of a susceptible age who had to share the same bedroom and come in pretty close contact with him all day long. I suggested that all three children should be given formamint tablets freely, and this was carried out with the result that despite their close contact the other children escaped the infection. This is only an isolated case, but it will certainly impel me to try the same experiment again. Mumps appears to me a disease for which this mode of treatment is peculiarly well adapted.

I hold no brief for this particular medicament, indeed, I think it one capable of considerable improvement, for the tablets dissolve too rapidly, and it would be better, in $\mathrm{my}$ opinion, if they were made more lasting-e.g., after the style of a jujube. The results obtained should stimulate pharmacists to the preparation of lozenges containing other antiseptics in a form such as will appeal to children and sensitive adults. Cases in which properly performed swabbing and donching have been successful are innumerable but $I$ have none presenting special points of interest. The less sensitive the throat and therefore the longer the swab can be held firmly in contact with the affected part the more successful will be the treatment. In a very few cases I have applied powders either on dry swabs of cotton. wool or by insufflation to ulcerated fauces and tonsils. The chief difficulty is to find the exact site of the ulcer or ulcers, and it is sometimes quite impossible to locate them; in such a case it is useless to apply any powder on the off chance that you may cover the ulcerated patch. The most useful one for infective throat conditions is very finely powdered boric acid. Another for use in more severe cases is boric acid containing from $\frac{1}{2}$ to 1 per cent. of lysoform. Powders must only be applied in very small amounts and with the greatest care to avoid possible irritation of the larynx.

The results then go to show that for throat disinfection gargling possesses no advantages, but, on the contrary, several serious disadvantages; that spraying is little better than gargling; and that the only reliable methods are swabbing and douching. Medication by antiseptic lozenges is an ideal line of treatment, in my opinion; it has been signally successful in my hands and $I$ hope to see it considerably developed.

I cannot conclude without emphasising the necessity which my experience shows me is well recognised in hospitals but rarely is so in private practice-probably on account of the difficuity involved-of treating the post-nasal region as well as the fauces in almost all diseases of the throat and without exception in all infective conditions. The extra time and trouble necessitated will receive full repayment in the shape of much earlier cure. And my experience in such post-nasal conditions has led me to regard sulphate of zinc (one or two grains at most to the ounce) as one of the most useful remedies we possess. The nasal douching must be done in the most gentle manner possible, and when the condition is showing signs of abatement it is better to stop the douching altogether and to 
let nature complete the cure unaided. The continuance of those troublesome nasal discharges following on scarlet fever, diphtheria, measles, and the like is due in the majority of cases to improper prolongation of treatment.

Upper Gloucester-place, N.W.

\section{ACQUIRED DIVERTICULA OF THE SIGMOID FLEXURE,}

CONSIDERED ESPECIALLY IN RELATION TO SECONDARY PATHOLOGICAL PROCESSES AND THEIR CLINICAL SYMPTOMS.

BY W. H. MAXWELL TELLING, M.D., B.S. LOND., M.R.C.P. LOND.,

ASSISTANT PHYSIICIAN TO THE GENERAL INFIRMARY AND TO THE HOSPITAL FOR WOMEN AND CHLLDREN AT LEEDS; CLINICAL TECTUDER ON MEDTCINT AND DEMONTTRATOP TN MIEDICAT PATHOLOGY IN THE UNIVERSTTY OF LEEDS. (Concluded from page 850.)

Clinicat aspects.

THE clinical importance of these diverticula needs no further emphasis than that given by the number and gravity of the collected cases; yet it is only since Graser's communication in 1898 that the consequences of false diverticula of the sigmoid flexure have been seriously considered by the operating surgeon. But the time has come when no resourceful surgeon can afford to overlook the incidence of such cases; indeed, it is to the surgeon that we shall mainly look for an increase of our facts concerning them. It is by the "pathology of the living," as Moynihan happily phrases it, that we shall attain a proper clinical perspective with regard to them. One is almost constrained to think that we morbid anatomists have been a little slow in our appreciation of the pathological " possibilities" of acquired diverticula; certainly priority of observations " rests almost entirely with our surgical colleagues. The foregoing pathological summary makes it scarcely necessary to attempt a detailed clinical differentiation of the various types of case ; indeed, it would not be easy, for there would necessarily be much overlapping. But the great majority of the cases present themselves to the clinician in one of the four following ways, a few points concerning which yet remain to be mentioned.

1. Inflammatory trouble, more or less aonte, in the left lower abdomen (left-sided "appendisitis," sigmoiditis, peri-sigmoiditis, epiploio appendioitis, divertionlitis, peri. divertioulitis). - Inflammatory cases of this type constitute a large and important group. Many of them are clinically identical with the various types of inflammation of the vermiform appendix (Nothnagel (54)*), except for the fact that the trouble is on the left side. So strong is the resemblance that in Bland-Sutton's case (No. 57) the question of transposition of viscera was carefully considered. Moreover, just as we are familiar with many cases of appendicitis which clear up entirely, there can be no doubt that this may happen in cases of "diverticulitis," and this latter, as we have seen, is very frequently indeed a true " epiploic" appendicitis. Such cases, coming neither to operation nor necropsy, are difficult to verify; yet a number of very suggestive ones have been put on record (Mayo (48), Patel (56), D'Arcy Power (14), and others). Moreover, the history of earlier inflammatory troubles noted in some of the cases proves the point. In the study of sigmoiditis (of which diverticula are becoming increasingly recognised as an important and frequent cause) the existence of cases which clear up is established beyond doubt (Tuffier (72)). Patel, indeed, says : "Peut-être un jour sera-t-on en droit de dire que, dans presque tous ces cas décrits sous le nom de sigmoidites, il s'agit de véritables diverticulites, absolument comme l'appendicite a été substitutée peu à peu à la typhlite." We may therefore hope to learn to recognise them as accurately, if not as frequently, as we do the analogous cases in the right iliac region. Georgi (21) emphasises the fact that in most cases there is at first marked inflammation of the diver. ticulum without symptoms. When these occur, the earliest are a little pain, aggravated by constipation, in the neighbourhood of the sigmoid flexure, and some sensitiveness to pressure ; in marked cases a tumour is to be felt.

Left-sided tumour and absoess formation is a striking

* The parenthetical figures throughout the article relate to the bibliography at the end. feature. In 63 cases a tumour was felt in 20 and abscess formation occurred in 23 , though not in all cases giving rise to tumour, for the reasons given above. Georgi has further pointed out that with considerable pus formation there may be but little pain and no pyrexia.

In cases of sigmoiditis a characteristic tumour is often felt; it is elongated, sausage-shaped, tender, and often illdefined; it may be moveable or fixed, lying a little above Poupart's ligament (frequently parallel with it). Shortly after the occurrence of abdominal symptoms referable (more or less definitely) to this quarter of the abdomen, this swelling may be made out : it may disappear, rapidly or gradually, or may increase, with signs of pus formation

So far, the correct diagnosis of diverticular inflammation has apparently only once been suggested (by Mayo, Case 42). The suggestion would only be reasonakle in a patient of middle age or older and who was the subject of marked or former constipation. Inflammatory trouble of the above kind occurring in such a patient would at the best render a diagnosis of diverticulitis very uncertain; it would be much easier to label a case sigmoiditis, one of the commonest causes of which is constipation (Capasso (8)).

The chief conditions to be considered in differential diagnosis would appear to be (a) ordinary appendicitis with left-sided symptoms; $(b)$ pelvic inflammations; (c) ovarian cysts with strangulation or inflammation; (d) actinomycosis of the sigmoid flexure; and (e) syphilitic and tuberculous pericolitis. This list does not exhaust the possible sources of error ; diagnoses of pancreatic, ovarian, and cæcal tumours have each been made. There seems to be a tendency to accept too readily tuberculosis as the cause of some of these non-malignant strictures of the sigmoid flexure; and F. S. Kidd (41), in discussing the differential diagnosis of these hyperplastic tuberculons cases, does not even mention the stenosis of diverticular origin.

2. Intestinal obstruotion,-When acute this is probably due to secondary involvement of a coil of small intestine (Cases 59 and 50), and the initial cause is practically undiagnosable except at operation, where, however, its recogni. tion may be of considerable importance. Chronic obstruction of the small intestine, of which my case, No. 51, is the only example, must also be similarly difficult as regards diagnosis. When obstruction occuns it is usually chronic, or recurrent, or acute upon chronic. It is generally localisable to the sigmoid region (to the ileo-cæcal in Case 80), and nearly always leads to a diagnosis of carcinoma. In the 25 cases in which there was stenosis of the bowel, in at least 12 the diagnosis of carcinoma was made, either before or at the operation; but in many the diagnosis is not mentioned. In England this mimicry of carcinoma has been referred to by Monsarrat (49), but Moynihan (51) alone has given it the emphasis which its importance deserves. The differential diagnosis from malignant disease is extremely difficult. Very advanced age, a comparatively recent constipation, marked cachexia and blood in the stools, all favour strongly the presence of carcinoma; while long-standing constipation, the absence (after repeated examinations) of blood from the stools, and slight cachezia together with any evidences of pus formation would suggest the possibility of a peri-diverticulitis; entire absence of constipation may occur with either condition, and blood has been found in the stools in at least one case of diverticular origin (No. 59). Many observers (Bland-Sutton (4), Gordinier and Sampson (22)) have no doubt that "cures" of cancer in this region have been due in some cases to the fact that the lesion has been one of simple inflammation and probably diverticular ; Tuffier (42) quotes a very striking case. The proceedings may be greatly modified by a correct diagnosis at the time of operation. In some cases regarded as malignant further measures have been abandoned or a merely palliative operation (e.g., colotomy) performed, the amount of adhesion being regarded as a bar to more radical proceedings. These may, of course, be impossible whether the adhesions be due to simple inflammation or to malignant disease, but in one or two cases microscopic examination has revealed the absence of malignant disease and a radical operation has been then successfully carried out.

3. Perforative peritonitis.-Cases of this kind, in which the site of perforation is undiscoverable at the laparotomy, occur from time to time in the experience of every surgeon. It will scarcely be necessary to say now that a routine examination of the sigmoid region should always be made, with especial care if the age and previous history render the presence of diverticula in the least degree possible. 